FedUni ResearchOnline

https://researchonline.federation.edu.au

This is the accepted version of the following article:

Tolooiyan, A., Hemmingway, P., (2014). A preliminary study of the effect of groundwater flow on the thermal front created by borehole heat exchangers. International Journal of Low-Carbon Technologies Vol. 9, no. 4 (2014), p. 284-295; which has been published in final form at

https://doi.org/10.1111/gwat.12256. This article may be used for noncommercial purposes in accordance with Wiley Terms and Conditions for SelfArchiving. 


\title{
A preliminary study of the effect of groundwater flow on the thermal front created by borehole heat exchangers
}

\author{
Ali Tolooiyan ${ }^{1 \star}$ and Phil Hemmingway ${ }^{2}$ \\ ${ }^{1}$ Geotechnical and Hydrogeological Engineering Research Group (GHERG), Monash \\ University, Victoria, Australia; ${ }^{2}$ School of Biosystems Engineering (formerly School of Civil, \\ Structural and Environmental Engineering), University College Dublin, Dublin, Ireland
}

${ }^{\star}$ Corresponding author. tolooiyan@gmail.com

\begin{abstract}
An analysis of the effects that groundwater flow has on the thermal regime created by a ground source energy system is presented. The change in the development of the sub-surface thermal regime caused by a groundwater flow across a site, relative to a scenario where groundwater flow does not exist, is examined. Analysis is performed using bespoke finite-element formulations of both single- and multi-borehole systems. The results of this work show that even a modest groundwater flow across a site can lead to a significant change in the development of the sub-surface thermal regime.
\end{abstract}

Keywords: geothermal energy; groundwater flow; finite element; closed loop; heat transfer

Received 21 June 2012; revised 24 October 2012; accepted 5 November 2012

\section{INTRODUCTION}

A closed loop ground source energy (or geothermal energy) system operates by exchanging heat with the sub-surface via a circulating heat carrier fluid flowing around piping infrastructure which is buried in the ground. Closed loop geothermal systems are typically categorized as either horizontal, where the piping infrastructure is installed close to the surface in a horizontal orientation, or vertical, where the piping infrastructure is installed in a vertical orientation. Open loop geothermal energy systems operate by pumping water from an aquifer, exchanging heat using a heat pump and either returning water to the aquifer or disposing it via a surface discharge system or sewer. Open loop geothermal systems are inherently more risky than closed loop geothermal systems; open loop geothermal systems can require on-going maintenance throughout their operation and typically require detailed and therefore costly site investigations (e.g. chemical analysis of waters) at the system feasibility stage [1]. This paper deals with vertical closed loop geothermal systems only. These systems can range in size from single-borehole systems, which provide space heating and/or cooling to single-family dwellings or small offices, up to large multi-borehole installations, which may be suitable for heating and/or cooling of large multi-storey buildings and structures.
Calculating the required quantity of sub-surface piping infrastructure required to satisfy the heating and cooling loads of a proposed project is a critical stage in the design of a closed loop ground-source energy system. For soils where a high groundwater flow is present, the heat transfer process between the heat exchanger piping and the surrounding ground may be strongly influenced by convection effects; however, for formations with low hydraulic conductivity, the heat transfer process is typically dominated by heat conduction [2]. Banks et al. [3] found the phenomena of excessively high values of apparent thermal conductivity caused by the possible presence of groundwater flow across the tested borehole heat exchanger, to exist in 3 of 26 thermal response tests carried out in the UK. This indicates that groundwater flow design problems hampering the design of geothermal systems could be present in $\sim 10 \%$ of cases. However, it is noted that the existence of groundwater flow at a site is strongly related to the geology at the site and therefore in certain regions, design issues associated with the existence of groundwater flow may be prevalent.

A number of software packages have been developed to design and size closed loop ground source energy systems. Practically all of these software packages being used in the ground source energy industry (such as Energy Earth Designer [4] or GLHEPRO [5-7]) assume heat transfer by conduction only. This paper 
presents a preliminary investigation of the effect of groundwater flow on the development of the thermal front created by a singleborehole heat exchanger and group of borehole heat exchangers. The consequences of the altered shape and distribution of the thermal front created by a ground source energy system operating at a site effected by groundwater flow are not only important to understand from the perspective of the individual operating system but also important to consider the potential effect on adjacent or nearby ground source energy systems and potential future installations on neighbouring sites. An increase in the popularity of ground source energy systems (particularly in congested urban areas) means that it will become increasingly important to consider the interaction between adjacent or nearby ground source energy systems in the future $[8,9]$ and therefore development of numerical and finite-element formulations capable of quantifying the effect of groundwater flow of the sub-surface thermal regime is required.

\section{PREVIOUS WORK IN THE AREA}

The following paragraphs provide an overview of previous attempts made by researchers to understand the thermal influence imposed on a borehole heat exchanger system by groundwater flow. A large portion of the work done to date in this area has consisted of evaluating the effect that groundwater flow has on system efficiency (i.e. energy output) rather than on the sub-surface thermal regime. Several models have been constructed using TEMP/W and other softwares in order to consider the thermal effects of conductive heat flow on geotechnical engineering structures such as dams or embankments [10-14] in areas prone to permafrost.

A number of researchers have attempted to understand the implications of groundwater flow across a borehole heat exchanger using various approaches. Claesson and Eskilson [15] constructed an 'improved line source theory' to describe the effect of groundwater flow on a single-borehole heat exchanger under steady-state conditions and concluded that the thermal effect of natural groundwater movements homogenously spread over the ground volume is negligible. It should be noted however that Claesson and Eskilson [15] considered on a scenario where the ground formation was composed of rock. The worst-case scenario therefore presented by Claesson and Eskilson [15] relates to the effect of groundwater flow resulting from a ground formation with permeability $10^{-6} \mathrm{~m} / \mathrm{s}$ and gradient $1 / 66$. Following the well-known equation described by Darcy's law (flow velocity $=$ permeability $\times$ gradient), this means that the worstcase (or highest) flow rate considered by Claesson and Eskilson [15] is only $0.0013 \mathrm{~m} /$ day. The resulting findings that 'the thermal effect of natural groundwater movements are negligible' are therefore not considered applicable to cases where the geology may dictate a higher groundwater flow rate (for example the permeability of the gravels beneath the Cork Docklands in the South of Ireland is of the order of $5 \times$ $10^{-3} \mathrm{~m} / \mathrm{s}$ [1] and therefore if a hydraulic gradient equal to or greater than that assumed by Claesson and Eskilson [15] was present, the resulting sub-surface thermal effects due to the groundwater in this case would be significantly greater).

Lee and Lam [16] created a 3D finite-difference model capable of calculating the 'real' thermal conductivity of a ground formation from thermal response test field data provided by Pahud and Matthey [17] by take into account of the thermal influence of the water flow present across the tested borehole heat exchanger. Katsura et al. [18] present a method for determining the velocity of groundwater flow based on the temperature gradient observed from a thermal response test, thermal probe test and heating well method test. Chiasson et al. [19] found, using a 2D finite-element groundwater flow and mass/heat transport model, that groundwater flow can have a significant effect on borehole heat exchanger performance in cases where geological materials with high hydraulic conductivity or fractured rocks exist.

Wang et al. [2] present a simplified numerical approach to gain an understanding of the effect that groundwater flow has on the thermal performance (i.e. energy output) of a borehole heat exchanger. Comparison of results from a measurement campaign carried out on a borehole system which was being influenced by strong groundwater advection and the performance of the borehole system in the case of no groundwater advection (modelled using TRNSYS software [20]) indicated that the groundwater flow provided an average performance enhancement of the borehole heat exchanger energy injection/ extraction rate of 9.8 and $12.9 \%$ during summer and winter, respectively. The magnitude of the performance enhancement was found to depend to a large extent on the distribution and thickness percentage of the ground layer with the greatest groundwater flow. Nam et al. [21] performed a similar study by developing a simulation code capable of estimating the effect of groundwater flow on the energy output of an energy pile system. Fan et al. [22] reported a mathematical model and integrated it into a previously developed integrated soil cold storage and ground source heat pump simulation program. They concluded that the presence of groundwater flow significantly influenced the heat transfer between the borehole heat exchanger and the surrounding soil and therefore the energy output of the cold storage/ground source heat pump system.

Katzenbach et al. [23] carried out finite-element model (FEM) simulations in order to investigate the possible subsurface thermal influence on neighbouring properties caused by the operation of a geothermal seasonal thermal storage system in Frankfurt, Germany. Coupled conductive and convective heat transport models were created and the influence of varying boundary conditions was investigated. The project analysed consists of 302 foundation piles with diameters of up to $1.86 \mathrm{~m}$ and depths of up to $27 \mathrm{~m}$, of which 262 piles were equipped with heat exchanger pipes. The project also consists of a retaining wall of 543 piles ( $1.5 \mathrm{~m}$ diameter, up to $38 \mathrm{~m}$ length) of which every second reinforced pile was equipped with heat exchanger pipes, resulting in 130 retaining wall energy piles. Although exact details are not provided in 
Katzenbach et al. [23] and Katzenbach et al. [24] relating to the ground conditions at the site, it is understood that the majority of the pile depth is surrounded by relatively impermeable Frankfurt clay while a short, lower section of a portion of the piles is surrounded by higher permeability Frankfurt limestone where groundwater flow is present. It was observed that for a constant heat extraction rate, the groundwater flow causes a reduction in the temperature drop inside and adjacent to the borehole heat exchanger, and for a modelled flow velocity of $1 \mathrm{~m} /$ day results in a near-field temperature increase of $1.5^{\circ} \mathrm{C}$. Katzenbach et al. conclude that the horizontal groundwater flow results in the deflection of isotherms in the downstream direction, resulting in a larger thermally influenced area in the downstream direction of the energy foundation installation.

Gehlin and Hellström [25] created three 2D numerical finite difference model scenarios to investigate the short-term influence of the thermal effects of groundwater flow in fractured rock, resulting due to single or multiple fracture zones. Gehlin and Hellström conclude that significant enhancement of heat transfer properties is possible, even in cases where low specific flow rates exist in fractures, and recommend further investigation of the thermal effect of groundwater flow in nonvertical fractures and fractures crossing through boreholes, the long-term effects of fracture flow near a borehole heat exchanger and the influence of varying groundwater flow over time.

The influence of groundwater flow on thermal output of a borehole heat exchanger was examined by Clausen [26] for a range of flow velocities and aquifer thicknesses using a software package called finite-element sub-surface flow and transport simulation system [27]. The thermal performance of a borehole heat exchanger was investigated for flow rates ranging from 0 to $5 \mathrm{~m}$ /day (following from Chiasson et al. [19] who suggested typical groundwater flow rates of $4 \times 10^{-7} \mathrm{~m} /$ day in clay, $0.014-0.16 \mathrm{~m} /$ day in coarse sand and up to $8.4 \mathrm{~m} /$ day in gravel) and a range of vertical thicknesses of fracture planes containing horizontal flow across the borehole heat exchanger. Clausen [26] concluded that the existence of groundwater flow across a borehole heat exchanger (which has the effect of extracting heat from the ground unit under consideration) would lead to a significant improvement in the thermal performance of a ground source heat pump system injecting heat into the ground.

\section{FINITE-ELEMENT ANALYSIS}

The purpose of the finite-element analysis described in the following sections is to gain an understanding of the development of the sub-surface thermal front created by a borehole heat exchanger system and how it is affected by a flowing groundwater regime. This is achieved by integrating two finite-element software packages known as TEMP/W and SEEP/W [28, 29]. TEMP/W is a finite-element software program, which has been designed for the analysis of sub-surface thermal problems. The software can analyse both steady-state thermal conduction problems as well as transient problems and is typically used in industries to model freeze-thaw problems. SEEP/W is a finiteelement software program, which provides the facility to analyse groundwater seepage and excess pore-water pressure dissipation problems. The program allows analysis ranging from simple saturated steady-state problems to complex saturated/unsaturated time-dependent problems. TEMP/W has the ability to integrate with SEEP/W in order to take into account the convective heat transfer that occurs due to flowing water. The first stage in analysing the problem at hand is to construct a TEMP/W sub-surface heat conduction model, which is described in the next section.

\subsection{TEMP/W model formation}

A summary of the TEMP/W model construction and fundamental mathematical equations controlling the output of the FEM is outlined in this paper, readers should refer to Hemmingway and Tolooiyan [submitted for publication] and [30] for further details. Equation (1), where $F$ is the heat flux, $\lambda$ is the thermal conductivity, $T$ is the temperature and $x$ is distance, shows that heat flow due to conduction is directly dependent on the thermal conductivity of a material and temperature gradient. The negative sign in the equation indicates that temperature decreases in the direction of increasing $x$ when a positive heat flux is imposed on a material [31]. Heat flux due to conduction is governed by Equation (1) in TEMP/W analyses.

$$
F=-\lambda \frac{\partial T}{\partial x}
$$

The governing differential equation used in the formulation of TEMP/W is shown in Equation (2).

$$
\frac{\partial}{\partial x}\left(\lambda_{x} \frac{\partial T}{\partial x}\right)+\frac{\partial}{\partial y}\left(\lambda_{y} \frac{\partial T}{\partial y}\right)+Q=h \frac{\partial T}{\partial t}
$$

where $\lambda_{x}$ is thermal conductivity in the $x$-direction, $\lambda_{y}$ is thermal conductivity in the $y$-direction, $Q$ is applied heat flux and $h$ is capacity for heat storage of the soil-water-ice mixture [32]. This equation states that the difference between the heat flux entering and leaving an elemental volume of soil at a point in time is equal to the change in the stored heat energy.

The capacity to store heat is composed of two parts. The first part is the volumetric heat capacity of the material (either frozen or unfrozen) and the second part is the latent heat associated with the phase change. Equation (3) describes the capacity of a material to store heat, where, $c$ is apparent volumetric heat capacity of soil, $L$ is latent heat of water and $\Theta_{\mathrm{u}}$ is the total unfrozen volumetric water content. Several equations for estimating unfrozen and frozen volumetric heat capacity of soil are defined by DeVries [33] and Johnston et al. [34]. The latent heat associated with phase change can be ignored in this case because the model presented assumes that the ground and water contained therein will remain unfrozen for the period of the analysis, and therefore the change in total unfrozen volumetric water content $\left(\Theta_{\mathrm{u}}\right)$ is equal to zero, so that the capacity for heat storage of the soil under investigation 
is equal to the volumetric heat capacity of the soil. In this case, Equation (2) can be rewritten as Equation (4).

$$
\begin{gathered}
h=c+L \frac{\partial \Theta_{\mathrm{u}}}{\partial T} \\
\frac{\partial}{\partial x}\left(\lambda_{x} \frac{\partial T}{\partial x}\right)+\frac{\partial}{\partial y}\left(\lambda_{y} \frac{\partial T}{\partial y}\right)+Q=c \frac{\partial T}{\partial t}
\end{gathered}
$$

In order to include convective heat transfer effects, TEMP/W must obtain the water and air content and water and air velocity at every gauss point within the model for every time step. With this information, the partial differential equation for heat flow [Equation (2)] is modified to Equation (5) (GeoStudio [29] and Arenson et al. [35]).

$$
\begin{aligned}
\left(\rho_{\mathrm{s}} c_{\mathrm{ps}}+L \Theta_{\mathrm{w}} \frac{\partial \Theta_{\mathrm{u}}}{\partial T}\right) \frac{\partial T}{\partial t}= & \frac{\partial}{\partial y}\left[K_{\mathrm{t}} \frac{\partial T}{\partial y}\right]+c_{\mathrm{pa}} \frac{\partial\left(\dot{m}_{\mathrm{a}} T\right)}{\partial y} \\
& +\Theta_{\mathrm{w}} \rho_{\mathrm{w}} c_{\mathrm{pw}} \frac{\partial\left(q_{\mathrm{w}} T\right)}{\partial y}+Q
\end{aligned}
$$

where $\rho_{\mathrm{s}} c_{\mathrm{ps}}$ is the volumetric heat capacity of soil, $c_{\mathrm{pa} / \mathrm{w}}$ is the mass specific heat of air or water, $\Theta_{\mathrm{w}}$ is the volumetric water content, $\dot{m}_{\mathrm{a}}$ is the mass flow rate of air, $\partial \Theta_{\mathrm{u}} / \partial T$ is the slope of the unfrozen water content function, $q_{\mathrm{w}}$ is the specific discharge (Darcy velocity) of water and $L$ is the latent heat of water. Although the definition of $K_{\mathrm{t}}$ is not addressed in GeoStudio [29] or Arenson et al. [35], DeVries [33] and Shoop and Bigl [36] defined it using Equation (6), where $K_{\mathrm{t}}$ is thermal conductivity of the soil-water-ice mixture, $K_{\mathrm{w}}$ is thermal conductivity of water, $K_{\mathrm{i}}$ is thermal conductivity of ice, $K_{\mathrm{S}}$ is thermal conductivity of soil, $\Theta_{\mathrm{u}}$ is volumetric ice content and $\Theta_{0}$ is soil porosity.

$$
K_{\mathrm{t}}=K_{\mathrm{w}} \Theta_{\mathrm{u}}+K_{\mathrm{i}} \Theta_{\mathrm{i}}+K_{\mathrm{s}}\left(1-\Theta_{0}\right)
$$

Equation (5) can thus be modified to Equation (7) (where $c_{\mathrm{w}}$ equals the mass specific heat capacity of water $(4.187 \mathrm{~kJ} / \mathrm{kgK})$ because this study that the ground and water contained therein will remain unfrozen for the period of the analysis and that the ground is fully saturated (no air in the ground).

$$
c \frac{\partial T}{\partial t}=\frac{\partial}{\partial y}\left[K_{\mathrm{t}} \frac{\partial T}{\partial y}\right]+c_{\mathrm{w}} \frac{\partial\left(q_{\mathrm{w}} T\right)}{\partial y} \Theta_{\mathrm{w}}+Q
$$

\subsection{SEEP/W model formation}

SEEP/W is formulated on the basis that the flow of water through both saturated and unsaturated soil follows Darcy's Law which is shown in Equation (8), where $q_{\mathrm{w}}$ is the specific discharge (or Darcy velocity, as explained in Section 2), $k$ is the hydraulic conductivity and $i$ is the gradient of total hydraulic head.

$$
q_{\mathrm{w}}=k i
$$

Darcy's law was originally derived for saturated soil, but later research showed that it can also be applied to the flow of water through unsaturated soil (see Richards [37], Childs and Collis-George [38] and GeoStudio [28]). The only difference is that under conditions of unsaturated flow, the hydraulic conductivity is no longer a constant, but varies with changes in water content and indirectly varies with changes in pore water pressure (see Krahn [39] and Tolooiyan et al. [40]).

The general governing differential equation for $2 \mathrm{D}$ seepage can be expressed as Equation (9), where $T_{\mathrm{h}}$ is the total head, $k_{x}$ is the hydraulic conductivity in the $x$-direction, $k_{y}$ is the hydraulic conductivity in the $y$-direction, $Q_{w}$ is the applied water boundary flux and $t$ is time.

$$
\frac{\partial}{\partial x}\left(k_{x} \frac{\partial T_{\mathrm{h}}}{\partial x}\right)+\frac{\partial}{\partial y}\left(k_{y} \frac{\partial T_{\mathrm{h}}}{\partial y}\right)+Q_{\mathrm{w}}=\frac{\partial \Theta_{\mathrm{w}}}{\partial t}
$$

This equation states that the difference between the water flow (flux) entering and leaving an elemental volume at a point in time equals the change in storage of the soil systems. More fundamentally, it states that the sum of the rates of change of flows in the $x$ - and $y$-directions and the external applied water flux equals the rate of change of the volumetric water content with respect to time. The right side of Equation (9) is zero, so the flux entering and leaving an elemental volume is the same at all times in the case of the analysis presented, because the ground is fully saturated and volumetric water content is assumed constant during the analysis time.

\subsection{FEM model design}

A 2D $20 \mathrm{~m} \times 20 \mathrm{~m}$ soil cluster is defined in plan view. For the single-borehole analysis, a borehole is placed at the centre of the cluster as shown in Figure 1. The construction includes 6700 elements, consisting of both quad (integration order of 4) and triangular (integration order of 3) elements. Rectangular grids of infinite elements are formed on the basis of a decay shape function and placed at the outer extents of the model geometry (see the lower right segment of Figure 1). TEMP/W and SEEP/ $\mathrm{W}$ code uses a formulation developed by Bettess [41] to model infinite elements. To use this formulation, the relationship between local and global coordinate systems must be described

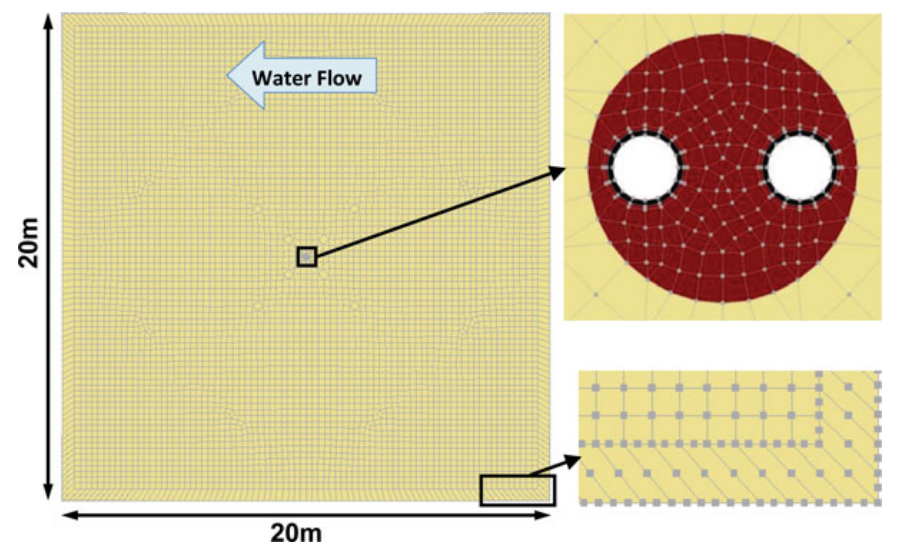

Figure 1. Soil cluster with centralized borehole. 
by a shape function. TEMP/W and SEEP/W use the Serendipity family of mapping functions presented by Bettess [41] to make the relationship between the local and global coordinate systems $[28,29]$. This function is related to the placement of infinite element in the model geometry and can be written in five different forms for $1 \mathrm{D}$ infinite elements and three different forms for 2D infinite elements. These infinite elements are a convenient way of extending the far field of a problem and in general three points are required to describe the shape function. Each element needs to be an eight-noded quadrilateral, so secondary nodes are required to form the decay function. For more information, readers are referred to Bettess [41] and GeoStudio ([28, 29], pp. 234-240). Utilization of the infinite elements on boundaries therefore effectively extends the finite-element geometry beyond the $20 \mathrm{~m} \times 20 \mathrm{~m}$, without the need to increase the model geometry size beyond the $20 \mathrm{~m} \times 20 \mathrm{~m}$ boundary (which would have the potential effect of reducing the accuracy of the model). In the convection analyses which follow (denoted 'Cond. \& Conv.' in later sections to indicate that the effects of both conduction and convection are being taken account of) water flows from right to left with a constant velocity for each individual analysis.

For the multi-borehole analysis, four boreholes are placed at the right-hand side of the soil cluster at a distance $4.75 \mathrm{~m}$ from each other (see Figure 2). The construction includes 5650 elements, consisting of both quad (integration order of 4) and triangular (integration order of 3) elements. Rectangular grids of infinite elements are applied on boundaries as in the case of the single-borehole model construction.

The soil and borehole heat exchanger parameters selected for the analysis are shown in Table 1 . The chosen parameters are selected on the basis of the assumption that the borehole heat exchanger system in question is installed in a geological formation dominated by saturated sand and are commensurate with what could be expected under Irish geological and climactic conditions. A low permeability thermally enhanced grout of thermal conductivity $1.47 \mathrm{~W} / \mathrm{mK}$ is specified as the backfill

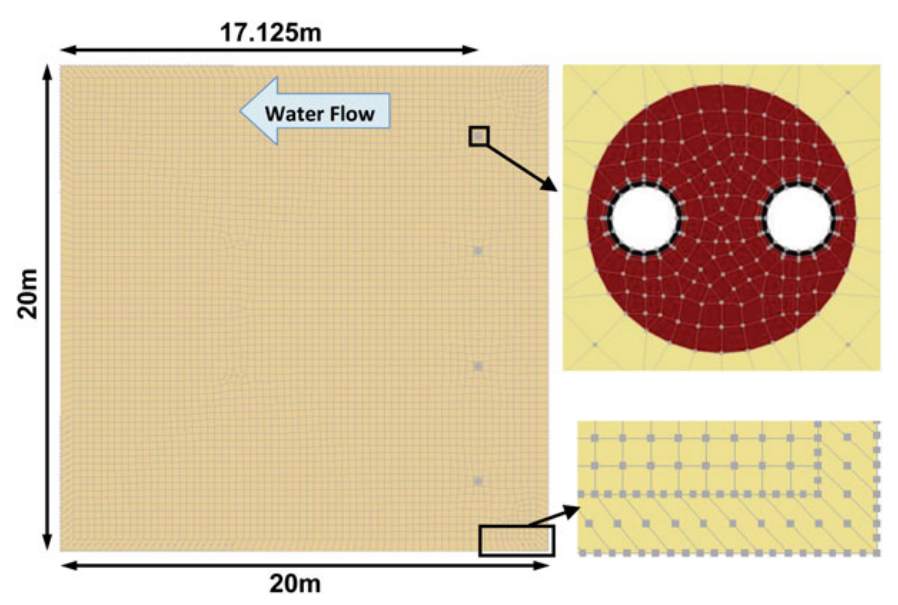

Figure 2. Soil cluster with multi-boreholes.
Table 1. Soil and borehole heat exchanger parameters.

\begin{tabular}{lc}
\hline Parameters & Assigned value \\
\hline Soil cluster thermal conductivity $(\mathrm{W} / \mathrm{mK})$ & 2.4 \\
Soil cluster volumetric heat capacity $\left(\mathrm{MJ} / \mathrm{m}^{3} \mathrm{~K}\right)$ & 2.5 \\
Backfill material thermal conductivity $(\mathrm{W} / \mathrm{mK})$ & 1.47 \\
Backfill material volumetric heat capacity $\left(\mathrm{MJ} / \mathrm{m}^{3} \mathrm{~K}\right)$ & 1.8 \\
Pipe thermal conductivity $(\mathrm{W} / \mathrm{mK})$ & 0.42 \\
Pipe volumetric heat capacity $\left(\mathrm{MJ} / \mathrm{m}^{3} \mathrm{~K}\right)$ & 1.95 \\
Average ground surface temperature $\left({ }^{\circ} \mathrm{C}\right)$ & 9.9 \\
Geothermal heat flux $\left(\mathrm{W} / \mathrm{m}^{2}\right)$ & 0.07 \\
Pipe outer diameter $(\mathrm{mm})$ & 40 \\
Pipe wall thickness $(\mathrm{mm})$ & 3 \\
Spacing between pipes $(\mathrm{mm})$ & 80 \\
Borehole diameter $(\mathrm{mm})$ & 140 \\
\hline
\end{tabular}

material surrounding the pipes. A long-term averaged specific heat extraction rate representing a constant building heating base load of $2.5 \mathrm{MWh}$ per month is assumed in the analysis. The information shown in Table 1 alongside some additional data presented in detail in Hemmingway and Tolooiyan [submitted for publication] is entered into a borehole heat exchanger dimensioning design tool called Energy Earth Designer [4] and a period of 25 years is simulated. This simulation indicates that a borehole heat exchanger of length $108 \mathrm{~m}$ is required to meet the specified heating loads over a period of 25 years.

The design tool also provides monthly values for the average borehole heat exchanger fluid temperature (i.e. the average temperature of the fluid in each of the borehole heat exchanger pipes), the first 24 months of which (shown in Figure 3 ) is used as the input values for the TEMP/W model.

To model both conduction and convection, and consider the water flow effectsa coupled heat transfer FEM (TEMP/W and SEEP/W) is employed. In addition to the parameters shown in Table 1, a number of other parameters are required to model the water flow and heat convection. These parameters are shown in Table 2.

\section{ANALYSIS AND RESULTS}

\subsection{Single-borehole analysis}

Analysis is performed using both TEMP/W (for conduction only) and coupled TEMP/W-SEEP/W (for conduction and convection) FEMs in order to provide a graphical representation of the variation in heat propagation from the borehole heat exchanger for a number of time steps. In the initial analysis, a water flow velocity of $0.16 \mathrm{~m} /$ day is assumed which is representative of a typical flow rate, which might be found in a geological formation dominated by sand [19]. Three grid independence tests consisting of 38900,6700 and 2002 elements were carried out alongside a time step independence test consisting of 48,24 and 1 time step(s) in order to validate the numerical accuracy of the model. The dependency test results revealed that the model outputs are independent of the 


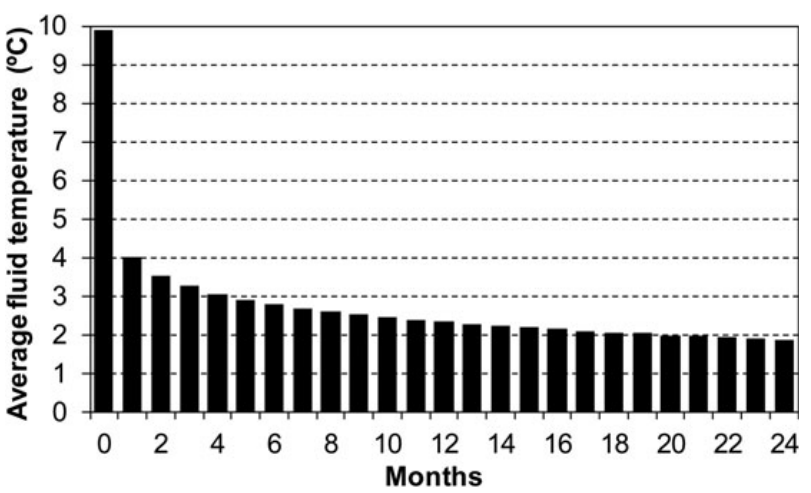

Figure 3. Average borehole heat exchanger fluid temperature.

Table 2. Additional parameters for modelling water flow and heat convection.

\begin{tabular}{lc}
\hline Parameters & Assigned value \\
\hline Soil cluster permeability $(\mathrm{m} /$ day $)$ & 432 \\
Soil cluster volumetric water content $\left(\mathrm{m}^{3} / \mathrm{m}^{3}\right)$ & 0.3 \\
Backfill material permeability $(\mathrm{m} /$ day $)$ & $1.9008 \mathrm{e}-5$ \\
Backfill material volumetric water content $\left(\mathrm{m}^{3} / \mathrm{m}^{3}\right)$ & 0.36 \\
\hline
\end{tabular}

considered grid and time steps. Figure 4 shows the heat flow profiles after 8,16 and 24 months where the temperature difference between each iso-counter line is $0.5^{\circ} \mathrm{C}$. Each of the subfigures on the left-hand side of Figure 4 represents a conduction only modelled scenario (denoted 'Cond. Only') for a particular time step, while each of the sub-figures on the right-hand side represent a coupled conduction and convection modelled scenario (denoted 'Cond. \& Conv.') for the same time step. The water velocity is held constant at $0.16 \mathrm{~m} /$ day throughout each of the 8-, 16- and 24-month scenarios. It is clear from visual comparison of the sub-figures on the left and right of Figure 4 that even a modest flow rate can have quite a significant effect on the thermal regime created by a single-borehole heat exchanger. This indicates that a thorough understanding of the groundwater flow regime at a potential closed loop ground source energy installation site and in the wider surrounding area is important so that (i) the implications of groundwater flow can be understood in terms of interaction between borehole within the site; (ii) the sub-surface thermal effects on neighbouring sites where one may wish to install or may already have installed a ground source energy system can be understood; (iii) the potential sub-surface thermal effects on the proposed system (and associated design implications, e.g. factor of safety) which could be effected by future ground source energy systems in the area and (iv) an understanding of how the groundwater flow may affect the performance of the proposed system and whether or not many of the established ground source energy industry software packages (such as Energy Earth Designer [4] or GLHEPRO [5-7]) can be used with confidence, given that they assume sub-surface heat transfer to occur by conduction only. The sub-surface thermal effects of groundwater flow for a multi-borehole system are illustrated in Section 4.2.

A comparison between the development of sub-surface thermal regime caused by a single-borehole heat exchanger may be made by comparing the predictions made by Claesson and Eskilson's [15, 42] closed form radial heat transfer equation [Equation (10)], the TEMP/W (conduction only) FEM described in detail in Hemmingway and Tolooiyan [submitted for publication] and [30] and the coupled TEMP/W-SEEP/W (conduction and convection) FEM defined in this paper.

Claesson and Eskilson's closed form radial heat transfer equation [Equation (10)] was defined in order to describe radial heat transfer in the vicinity of a closed loop borehole heat exchanger extracting or injecting heat from/to the subsurface and confirms the accuracy of the output from the conduction analysis performed using TEMP/W.

$$
T \approx T_{0}-\frac{q}{4 \pi \lambda}\left[\ln \left(\frac{4 \lambda t}{r^{2} S_{\mathrm{VC}}}\right)-0.5772\right]
$$

where $T$ is the temperature at time $t$ and $r$ is the distance from the centre of the borehole heat exchanger, $T_{0}$ is the initial undisturbed ground temperature prior to application of a heating load, $q$ is the specific heat extraction rate of the borehole heat exchanger $(\mathrm{W} / \mathrm{m}), \lambda$ is the thermal conductivity of the rock/ soil being analysed $(\mathrm{W} / \mathrm{mK})$ and $S_{\mathrm{VC}}$ is the specific heat capacity $\left(\mathrm{Ws} / \mathrm{m}^{3} \mathrm{~K}\right)$ of the rock/soil being analysed. The equation is valid within the range $5_{r_{\mathrm{b}}}^{2} S_{\mathrm{VC}} / \lambda<t<t_{\mathrm{s}} / 10$ [43], where $t_{\mathrm{s}}$ is the time at which 'steady-state' heat exchange begins, i.e. the point in time at which $3 \mathrm{D}$ heat flow effects become too great to ignore.

A comparison between the sub-surface temperature predicted using each of the three previously described methods (the closed form conduction only equation denoted 'C.f.'; the conduction only TEMP/W FEM denoted 'Cond.' and the coupled TEMP/W-SEEP/W conduction and convection FEM denoted 'Con. \& Conv.') caused by a single-borehole heat exchanger at a distance of $3 \mathrm{~m}$ from the borehole and time step 24 months is shown in Figure 5. The predictions of temperature at $3 \mathrm{~m}$ from the borehole heat exchanger in both the perpendicular and parallel directions to the flow are superimposed on the figure. The predictions made using both the closed form equation and the TEMP/W FEM (8.17 and $8.16^{\circ} \mathrm{C}$, respectively) show good agreement. The temperatures predicted by each of the respective conduction only methods are identical in all directions as expected because heat transfer by conduction only is being analysed and therefore propagates at an equal rate in all directions out from the borehole heat exchanger. The coupled TEMP/W-SEEP/W FEM prediction however shows an expected temperature of $8.27^{\circ} \mathrm{C}$ in the direction parallel (and downstream) to the flow, but a higher value of $9.51^{\circ} \mathrm{C}$ in the direction perpendicular to the flow. This is because the thermal influence of the borehole heat exchanger is being extended (or 'pulled') in the direction of the flowing groundwater. 

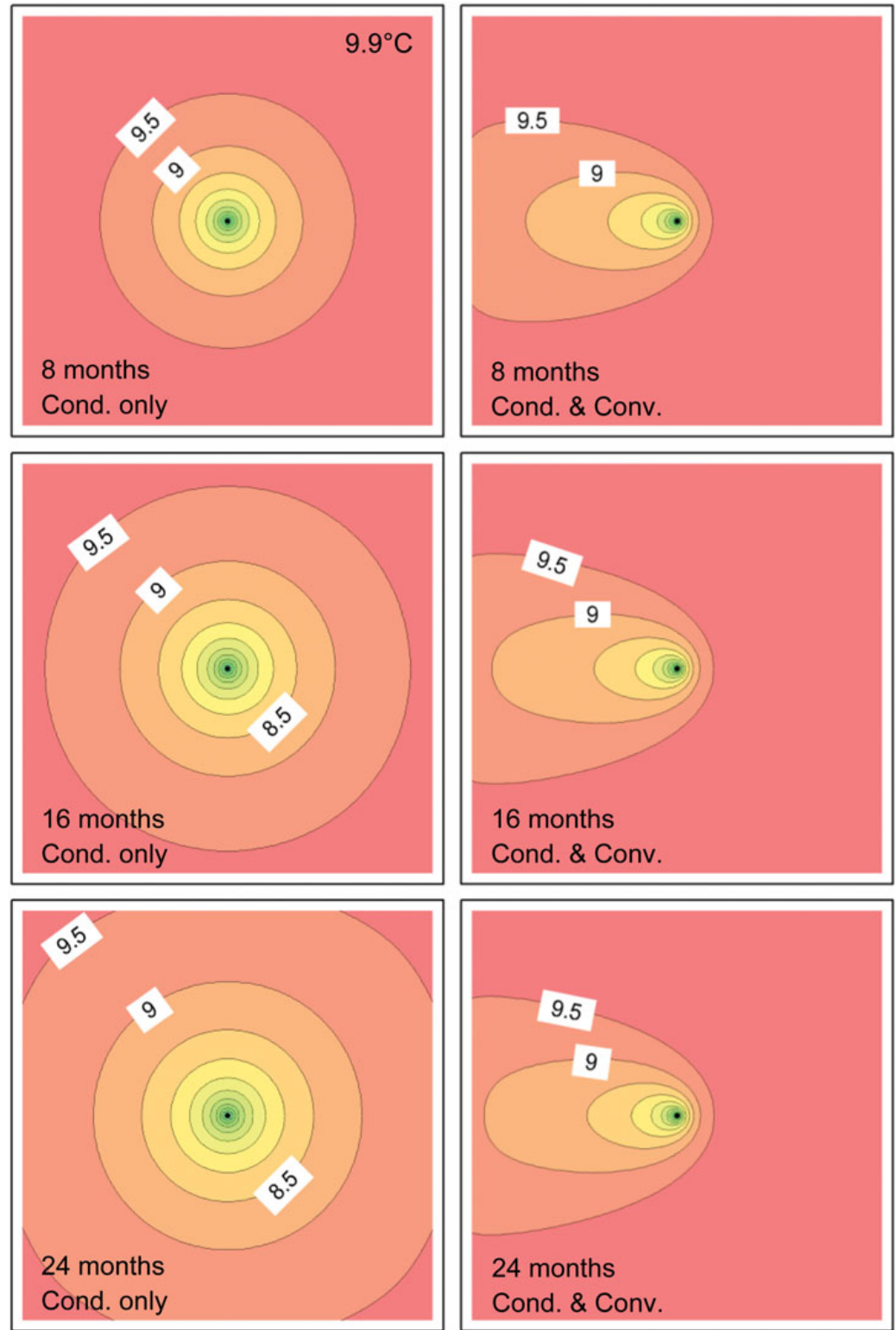

Figure 4. Heat flow profiles at various time steps (water flow velocity: $\left(0.16 \mathrm{~m} /\right.$ day); the temperature difference between each iso-counter line is $\left(0.5^{\circ} \mathrm{C}\right)$ and the numbers in the white text boxes refer to the temperature of the respective iso-counter lines, in ${ }^{\circ} \mathrm{C}$ ).

Comparison between the change in ground temperature from undisturbed conditions $($ time $=0$ ) to those after 24 months for a range of distances $(r)$ from the borehole heat exchanger according to the closed form equation, TEMP/W conduction only FEM and the coupled TEMP/W-SEEP/W conduction and convection FEM are shown in Figure 6a at distances parallel to the water flow and Figure $6 \mathrm{~b}$ at distances perpendicular to the water flow. The 24-month time step and maximum distance of $3 \mathrm{~m}$ from the borehole heat exchanger was chosen because the closed form equation is valid for analysis of heat transfer between $\sim 1.5$ and 3.8 years for a distance of $3 \mathrm{~m}$ from the a borehole heat exchanger as described earlier in this section introducing the closed form equation.
A good fit between the results modelled using the TEMP/W model and those obtained using the closed form equation (both assuming heat transfer by conduction only) is observed in Figure 6 for the range of distances $(r)$ from the borehole heat exchanger after 24 months. The closed form equation shows a decrease in the change in temperature relative to the initial ground temperature of $42.9 \%$ at $0.5 \mathrm{~m}$ from the borehole to a change of $16.0 \%$ at a distance of $3 \mathrm{~m}$ from the borehole heat exchanger, while the TEMP/W model shows a decrease of 38.0 and $16.0 \%$, respectively. Comparison between the method assuming heat transfer by conduction only (i.e. the closed form equation and the TEMP/W conduction model) and the coupled TEMP/W-SEEP/W model capable of 


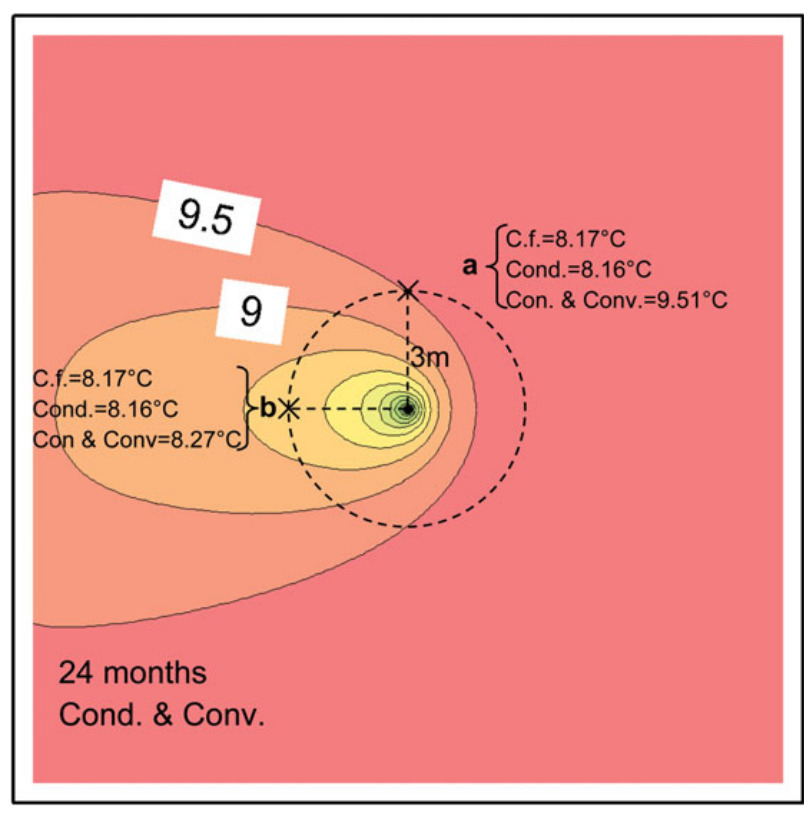

Figure 5. Analysis of temperature predictions at $3 \mathrm{~m}$ from the borehole and at 24 months by three methods (water flow velocity: $0.16 \mathrm{~m} /$ day).
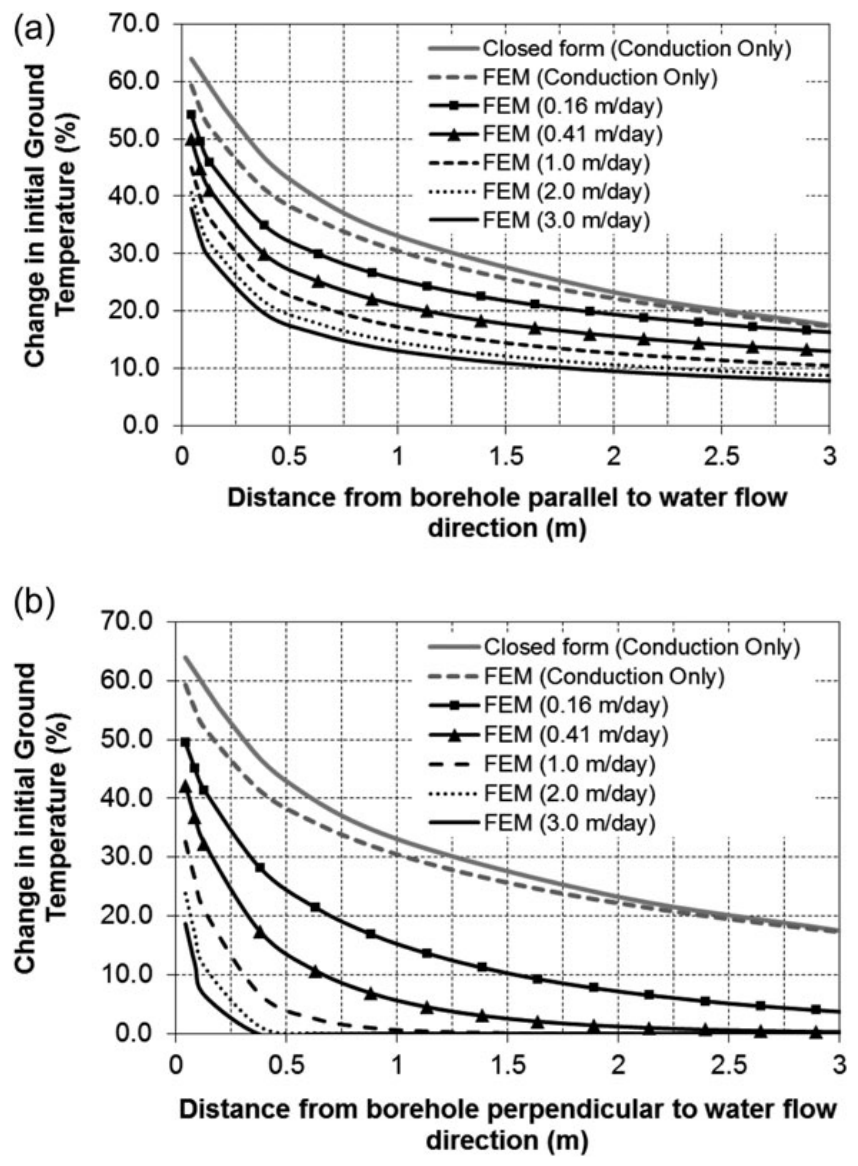

Figure 6. Change in temperature with distance (r) from the borehole heat exchanger after 24 months. (a) Parallel to the water flow direction and (b) perpendicular to the water flow direction. modelling heat transfer due to conduction and convection shows a significant difference in the predicted temperature with distance from the borehole heat exchanger. A graphical representation of the development of the ground thermal regime at 1 - and 24-month periods for flow velocities of 0.16 , 1.0 and $3.0 \mathrm{~m} /$ day is provided in Figure 7.

\subsection{Multi-borehole analysis}

A multi-borehole (or group borehole) analysis was performed using the conduction only TEMP/W and the coupled conduction and convection TEMP/W-SEEP/W models referred to earlier in this article, which were further developed to incorporate four boreholes as described in Section 3.3. Figure 8 shows the predicted development of sub-surface heat flow profiles after 8 , 16 and 24 months, with the conduction only TEMP/W models shown in the left-hand side sub-figures for each time step and the coupled conduction and convection TEMP/W-SEEP/W models shown in the right-hand side sub-figures.

As was the case for the single-borehole heat exchanger analysis, quite a significant difference in development profiles for the conduction only and coupled conduction and convection scenarios is observed in each of the 8-, 16- and 24-month time steps, with the decrease in ground temperatures created by the operating borehole heat exchanger being 'pulled' in the direction of water flow. The area of thermal influence created by the borehole heat exchanger system is therefore larger in the downstream direction and smaller in the upstream direction relative to a situation where no groundwater flow exists and therefore heat transfer occurs by conduction only. This difference is clearly illustrated by the drawing which is superimposed on the bottom two sub-figures of Figure 8. A straight line is drawn from the centre point between the two inner boreholes in the parallel direction to the water flow on the output sub-figures from both the TEMP/W and TEMP/W-SEEP/W 24-month analyses. The temperature at 'point d' (which is located a perpendicular distance of $5.6 \mathrm{~m}$ from the line of boreholes in the model) in the TEMP/W conduction only model is calculated to be $7.5^{\circ} \mathrm{C}$ while a temperature value of $6.94^{\circ} \mathrm{C}$ is observed at the same point in the TEMP/W-SEEP/W coupled conduction and convection model. Similarly, at 'point c' (which is located a perpendicular distance of $16.3 \mathrm{~m}$ from the line of boreholes in the model) temperature values of 9.5 and $7.45^{\circ} \mathrm{C}$ are observed for the TEMP/W and TEMP/W-SEEP/W models, respectively. The multi-borehole analysis endorses the findings made from the single-borehole heat exchanger analyses relating to the importance of gaining a thorough understanding the groundwater flow regime present at a site and its implication for thermal interaction of boreholes within a site, effects on neighbouring systems, potential thermal effects/interference caused by the installation of other ground source energy systems on nearby sites and design using the industry standard software packages. It is clear that the borehole heat exchanger layout for ground source energy systems with unbalanced annual energy requirements that should be selected in order to take most benefit from the 

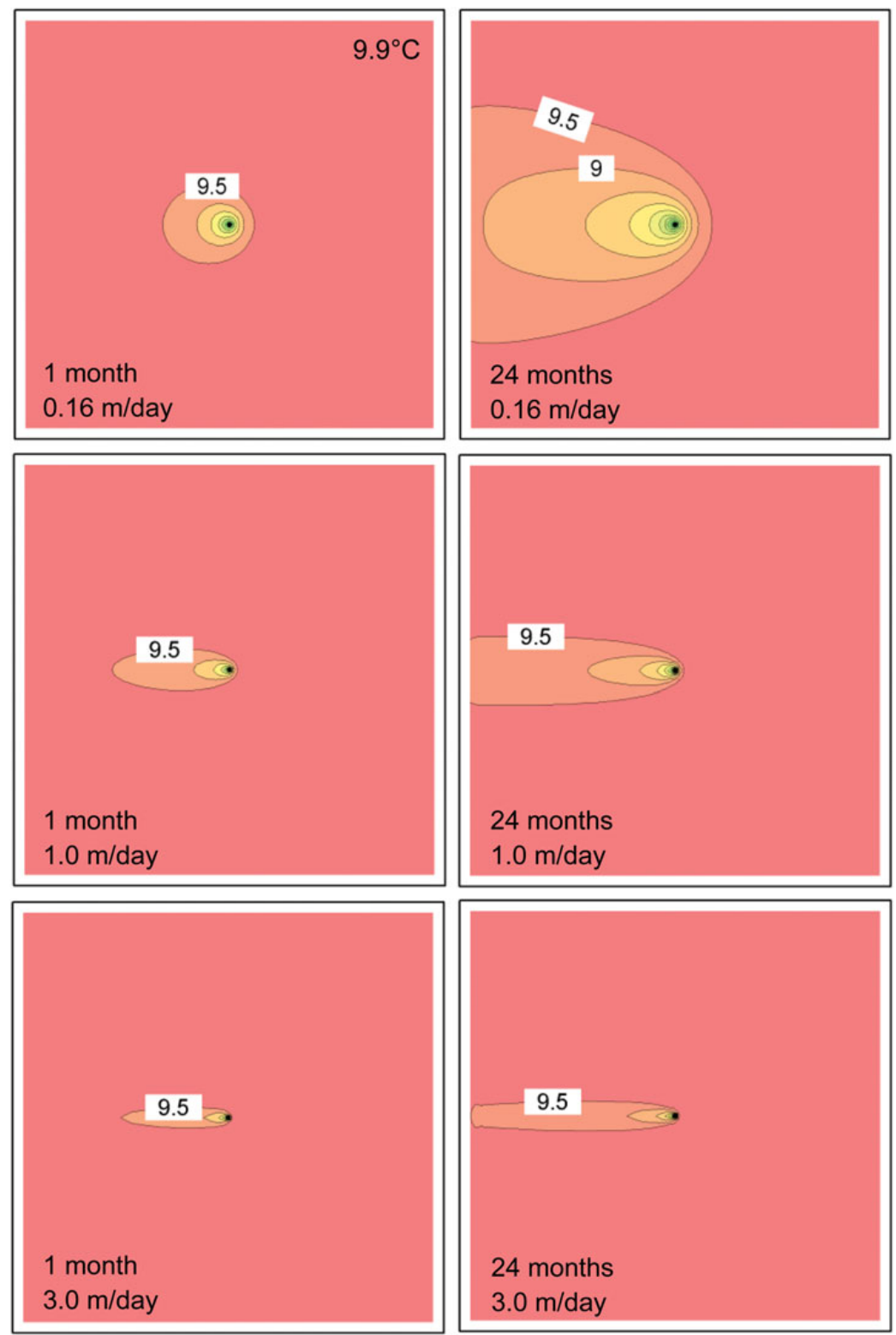

Figure 7. Development of the ground thermal regime at 1- and 24-month periods for flow velocities of 0.16, 1.0 and $3.0 \mathrm{~m} / \mathrm{day}$.

thermal recharge associated with a flowing groundwater is that which would reduce the quantity of thermal interaction between the borehole heat exchangers caused by the groundwater flow. In other words, they should be oriented perpendicular to the direction of water flow as shown in Figure 8.

\section{CONCLUSIONS}

FEMs have been constructed in order to gain an understanding of the change in the development of the sub-surface thermal regime for single and multi-borehole heat exchanger systems caused by a flowing groundwater regime. A FEM considering heat transfer to occur by conduction only is created using TEMP/W, while a model capable of analysing the effect of coupled conductive and convective heat transfer effects is created using a TEMP/W-SEEP/W model formulation. Comparison between the conduction only and the coupled conduction and convection models show that the groundwater flow has a significant effect on the development of the sub-surface thermal regime propagating from a borehole heat exchanger.

It is concluded that even a modest groundwater flow rate of $0.16 \mathrm{~m} /$ day can have a significant effect on the development of the thermal regime created by a single- or multi-borehole heat exchanger system. A thorough understanding of the groundwater flow regime at any proposed closed loop ground source energy system installation site is therefore important so that the associated implications of thermal interaction of the boreholes within the site, the potential effects on existing neighbouring systems, the potential interference with the proposed 

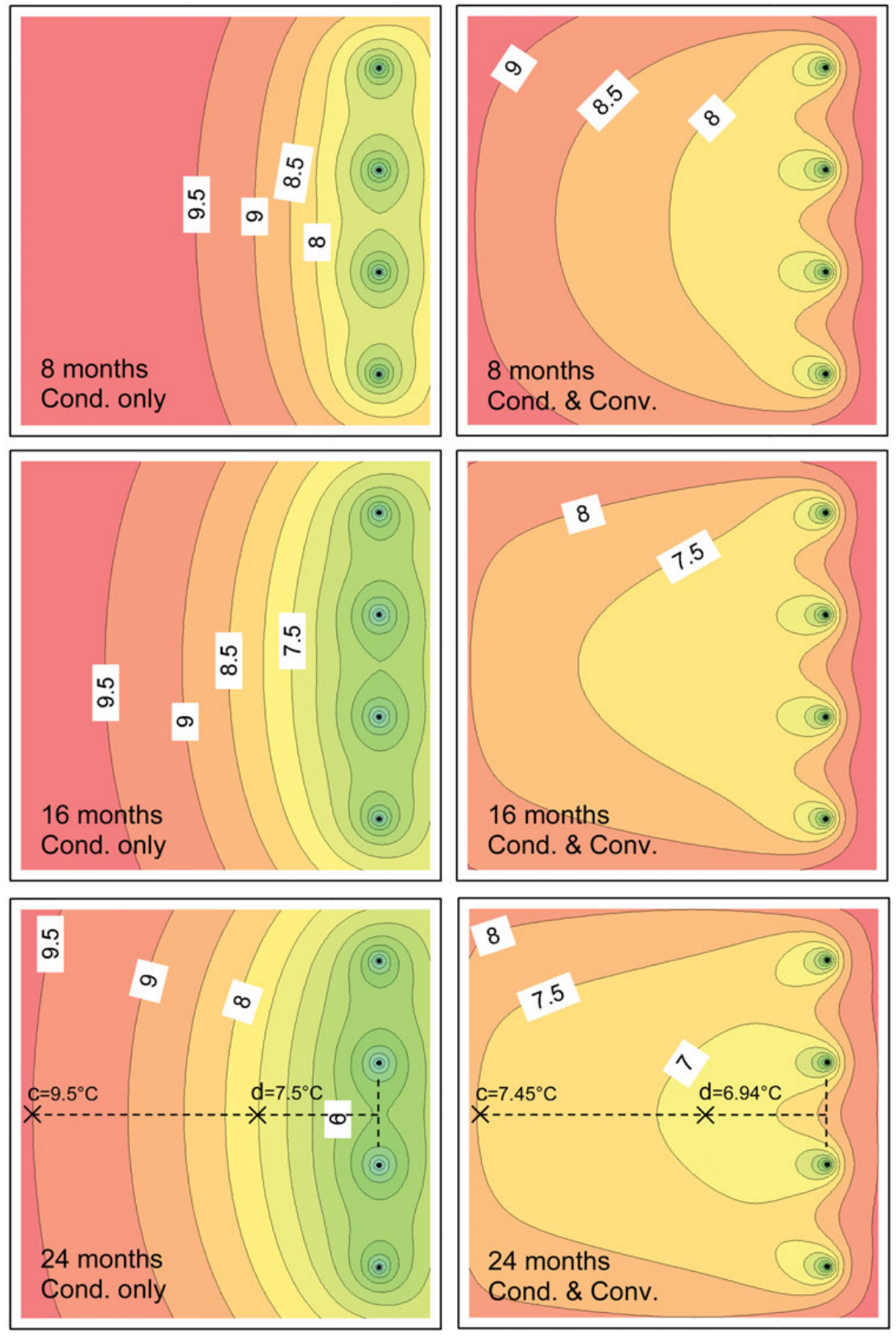

Figure 8. Heat flow profiles at various time steps for a multi-borehole scenario (water flow velocity: $0.16 \mathrm{~m} /$ day).

system which may be caused by installations of other ground source energy systems on nearby sites in the future and the effect of the groundwater flow on the performance of the system. It also raises questions as to whether or not many of the established ground source energy industry software packages (which typically assume that sub-surface heat transfer occurs by conduction only) can be used with confidence in areas where even low to modest groundwater flow rates are possible.

The results from the coupled conduction and convection analysis show that the optimal borehole heat exchanger layout for a ground source energy system with unbalanced annual energy requirements is one in which the borehole heat exchangers are oriented perpendicular to the direction of the water flow, as this reduces the groundwater flow-induced thermal interaction between borehole heat exchangers.

Further work in this area will involve developing the coupled conduction and convection FEM presented to produce a comprehensive database of results based on analyses for the varying parameters associated with a number of different soil types, detailed analysis of which may result in the establishment of a standardized methodology for accounting for the effects of groundwater flow on ground source energy systems. The FEM will also be developed to incorporate the capability to model fluid flow within the borehole heat exchanger pipe using computational fluid dynamics. 


\section{ACKNOWLEDGEMENTS}

The authors acknowledge Dr. Mike Long (Senior Lecturer, School of Civil, Structural and Environmental Engineering, University College Dublin, Ireland) who provided a comprehensive and useful review of this paper. This second author's Ph.D. research was funded by the Irish Research Council for Science, Education and Technology (IRCSET).

\section{REFERENCES}

[1] Hemmingway P, Long M. Geothermal energy: settlement and water chemistry in Cork, Ireland. In: Proceedings of the Institution of Civil EngineersEngineering Sustainability. 2011; Vol. 164(ES3), pp 213-24. University College Dublin Institutional Repository. http://hdl.handle.net/10197/13725.

[2] Wang H, Qi C, Du H, et al. Thermal performance of borehole heat exchanger under groundwater flow: a case study from Baoding. Energ Buildings 2009;41:1368-73.

[3] Banks D, Withers J, Freeborn R. An overview of the results of in-situ thermal response testing in the UK. In: 11th International Conference on Thermal Energy Storage-Effstock 2009: Energy Storage for Energy Efficiency and Sustainability. EMTF förlag, Stockholm, Sweden, 2009, 8 p.

[4] EED, Energy Earth Designer Ver.3.16. Blocon Sweden, 2010.

[5] Spitler J, GLHEPRO: A design tool for commercial building ground loop heat exchangers. In: Proceedings of the Fourth International Heat Pumps in Cold Climates Conference. Alymer, Quebec, August 17-18, 2000, 15 p.

[6] GLHEPRO, Ver.4.0, School of Mechanical and Aerospace Engineering. Oklahoma State University, 2006.

[7] Xu X, Spitler J, Modelling of vertical ground loop heat exchangers with variable convective resistance and thermal mass of the fluid. In: 10th International Conference on Thermal Storage, Ecostock 2006: Thermal Energy Storage Here and Now. Richard Stockton College of NJ, NJ, USA, 2006, 8p.

[8] Preene M, Powrie W. Ground energy systems: delivering the potential. Proc Inst Civil Eng Energy 2009;162:77-84.

[9] Preene M, Powrie W. Ground energy systems: from analysis to geotechnical design. Géotechnique 2009;59:261-71.

[10] Jantzer I. A documentation of the Eastern Suorva Dam Core. In: MS.c. Thesis. Department of Civil and Environmental Engineering, Division of Soil Mechanics, Lulea University of Technology, Lulea, 2005, 74 p.

[11] Kristensen L, Christiansen H, Caline F. Temperatures in coastal permafrost in the Svea Area, Svalbard. In: Ninth International Conference on Permafrost. University of Alaska Faribanks, USA, 2008, pp. 1005-10.

[12] Mottaghy D, Rath V. Latent heat effects in subsurface heat transport modelling and their impact on palaeotemperature reconstructions. Geophys J Int 2006;164:236-45.

[13] Mobley A, Barlow B. Analysis of flooding effects on a landfill permafrost containment system. In: International Conference on Permafrost, Zurich, Switzerland. Swets \& Zeitlinger, Lisse, The Netherlands, 2003, 771-6.

[14] Weaver J, Kulas J. Development of a numerical model to assess potential long-term thermal impact on permafrost temperatures at the Red Dog Mine, Alaska. In: International Conference on Permafrost. Zurich, Switzerland, Swets \& Zeitlinger, Lisse, The Netherlands, 2003, 1229-33.

[15] Claesson H, Eskilson P. Conductive heat extraction by a deep borehole: thermal analysis and dimensioning rules. Energy 1988;13:509-27.
[16] Lee C, Lam HN. Determination of groundwater velocity in thermal response test analysis. In: 11th International Conference on Thermal Energy Storage; Effstock 2009: Energy Storage for Energy Efficiency and Sustainability. EMTF förlag, Stockholm, Sweden, 2009, 8p.

[17] Pahud D, Matthey B. Comparison of the thermal performance of double u-pipe borehole heat exchangers measured in situ. Energ Buildings 2001;33:503-7.

[18] Katsura T, Nakamura M, Hori S, et al. Evaluation method of groundwater velocity applying the gradient of thermal response. In: 11th International Conference on Thermal Energy Storage; Effstock 2009: Energy Storage for Energy Efficiency and Sustainability. EMTF förlag, Stockholm, Sweden, 2009, 8 p.

[19] Chiasson A, Rees SJ, Spitler J. A preliminary assessment of the effects of ground-water flow on closed-loop ground-source heat pumps. ASHRAE Trans 2000;106:380-93.

[20] TRNSYS, Transient System Simulation Tool Ver. 16. Thermal Energy System Specialists, LLC, 2009.

[21] Nam Y, Ooka R, Hwang S. Development of a numerical model to predict heat exchange rates for a ground-source heat pump system. Energ Buildings 2008;40:2133-40.

[22] Fan R, Jiang Y, Yao Y, et al. A study on the performance of a geothermal heat exchanger under coupled heat conduction and groundwater advection. Energy 2007;32:2199-209.

[23] Katzenbach R, Clauss F, Waberseck T, et al. Coupled numerical simulation of geothermal energy systems. In: 12th International Conference of the International Association for Computer Methods and Advances in Geomechanics (IACMAG). Curran Associates, Inc., Goa, India, 2008, pp. 1170-79.

[24] Katzenbach R, Ramm H, Waberseck T. Recent developments in foundation and geothermal engineering. In: 2nd International Conference on New Developments in Soil Mechanics and Geotechnical Engineering. Near East University, Nicosia, North Cyprus, 2009, pp. 464-71.

[25] Gehlin S, Hellström G. Influence on thermal response test by groundwater flow in vertical fractures in hard rock. Renewable Energy 2003;28:2221-38.

[26] Clausen H. Durchführung von Simulationsrechnungen zum Einfluss Verschiedener Randbedingungen auf die Thermische Leistungsfähigkeit von Erdwärmesonden (Implementation of simulations on the influence of different boundary conditions on the thermal performance of geothermal probes). Ph.D. Thesis. Institute of Building Energetics, University of Stuttgart, 2008, $94 \mathrm{p}$.

[27] FEFLOW. DHI-WASY GmbH, Ver.5., 2003.

[28] GeoStudio, SEEP/W User Manual. GEO-SLOPE International Ltd, 2007.

[29] GeoStudio, TEMP/W User Manual. GEO-SLOPE International Ltd, 2007.

[30] Hemmingway P. Investigation of ground properties for ground source energy systems. Ph.D. Thesis. College of Engineering \& Architecture, School of Civil, Structural \& Environmental Engineering, University College Dublin 2012, 315 p.

[31] Krahn J. Thermal Modelling with TEMP/W, an Engineering Methodology. GEO-SLOPE International Ltd, 2004.

[32] Svec O. Frost heave control of a chilled gas pipeline. Cold Reg. Sci. Technol. 1981;4:215-25.

[33] DeVries DA. Thermal Properties of Soils. North Holland, Amsterdam, 1966, $382 \mathrm{p}$.

[34] Johnston GH, Ladanyi B, Morgenstern NR, et al. Engineering Characteristics of Frozen and Thawing Soils. John Wiley \& Sons, 1981.

[35] Arenson LU, Sego DC, Newman G. The use of a convective heat flow model in road designs for northern regions. In: EIC Climate Change Technology, 2006 IEEE. Institute of Electrical and Electronics Engineers (IEEE), Ottowa, Canada, 2006, 8 p. 
[36] Shoop SA, Bigl SR. Moisture migration during freeze and thaw of unsaturated soils: modelling and large scale experiments. Cold Reg. Sci Technol 1997;25:33-45.

[37] Richards LA. Capillary conduction of liquids through porous mediums. J Appl Phys 1931;1:318-33.

[38] Childs EC, Collis-George N. The permeability of porous materials. Proc $R$ Soc A 1950;201:392-405.

[39] Krahn J. Seepage Modelling with SEEP/W, an Engineering Methodology. GEO-SLOPE International Ltd, 2004.
[40] Tolooiyan A, Abustan I, Selamat MR, et al. A comprehensive method for analyzing the effect of geotextile layers on embankment stability. Geotext Geomembranes 2009;27:399-405.

[41] Bettess P. Infinite Elements. Penshaw Press, 1992, 55-85.

[42] Eskilson P. Thermal analysis of heat extraction of boreholes. Ph.D. Thesis. University of Lund, Department of Mathematical Physics, 1987, $222 \mathrm{p}$.

[43] Banks D. An Introduction to Thermogeology: Ground Source Heating and Cooling. Blackwell Publishing, 2008, 324 p. 